\title{
Slow development of ALS-like spinal cord pathology in mutant valosin-containing protein gene knock-in mice
}

\author{
HZ Yin ${ }^{1}$, A Nalbandian², C-I Hsu', S Li', KJ Llewellyn ${ }^{2}$, T Mozaffar ${ }^{1,3}$, VE Kimonis ${ }^{\star, 2}$ and JH Weiss ${ }^{\star 1,4}$
}

Pathological features of amyotrophic lateral sclerosis (ALS) include, in addition to selective motor neuron (MN) degeneration, the occurrence of protein aggregates, mitochondrial dysfunction and astrogliosis. SOD1 mutations cause rare familial forms of ALS and have provided the most widely studied animal models. Relatively recent studies implicating another protein, TDP-43, in familial and sporadic forms of ALS have led to the development of new animal models. More recently, mutations in the valosincontaining protein (VCP) gene linked to the human genetic disease, Inclusion Body Myopathy associated with Paget's disease of bone and frontotemporal dementia (IBMPFD), were found also to be associated with ALS in some patients. A heterozygous knock-in VCP mouse model of IBMPFD $\left(\mathrm{VCP}^{\mathrm{R} 155 \mathrm{H} /+}\right.$ ) exhibited muscle, bone and brain pathology characteristic of the human disease. We have undertaken studies of spinal cord pathology in $\mathrm{VCP} \mathrm{P}^{\mathrm{R} 155 \mathrm{H} /+}$ mice and find age-dependent degeneration of ventral horn MNs, TDP-43-positive cytosolic inclusions, mitochondrial aggregation and progressive astrogliosis. Aged animals ( 24-27 months) show electromyography evidence of denervation consistent with the observed MN loss. Although these animals do not develop rapidly progressive fatal ALS-like disease during their lifespans, they recapitulate key pathological features of both human disease and other animal models of ALS, and may provide a valuable new model for studying events preceding onset of catastrophic disease.

Cell Death and Disease (2012) 3, e374; doi:10.1038/cddis.2012.115; published online 16 August 2012

Subject Category: Neuroscience

Amyotrophic lateral sclerosis (ALS) is characterized by a number of pathological hallmarks, including selective motor neuron (MN) loss, intracellular inclusions, astrogliosis, and mitochondrial abnormalities. ${ }^{1}$ Whereas most cases are sporadic, $\sim 10 \%$ are familial and some of those are caused by mutations in the SOD1 gene. Although transgenic mutant SOD1 animals, which provide the most widely studied models of the disease, display many of these features, ${ }^{1,2}$ therapeutic efficacy in these animals has been poorly predictive of human efficacy, and it is not clear the degree to which studies in these models overexpressing a gene implicated in a small subset of human cases will prove applicable to human disease.

An important breakthrough came with the relatively recent findings implicating roles of an unrelated protein, TDP-43 in familial as well as sporadic ALS. ${ }^{3,4}$ TDP-43 containing inclusions are found in both forms of the disease, and mutations in TDP-43 are associated with some familial forms of ALS. Interestingly, TDP-43 pathology is also associated with forms of frontotemporal dementia (FTD), suggesting some mechanistic overlap between these neurodegenerative diseases. ${ }^{3-6}$
Elucidation of the link between TDP-43 and ALS has led to the recent development of some new animal models. ${ }^{7}$ Although the mechanism of injury is still unclear, ${ }^{8}$ TDP-43 is normally a nuclear RNA/DNA-binding protein involved in multiple aspects of RNA metabolism, and, in disease, often appears in cytosolic inclusions. Suggesting a broad relevance of consequent mechanisms, a related RNA/DNA-binding protein, fused in sarcoma (FUS), is also associated with forms of FTD and ALS. ${ }^{6}$

Mutations in an unrelated gene, valosin-containing protein (VCP), were previously found to be associated with a genetic disease, Inclusion Body Myopathy associated with Paget's disease of bone and frontotemporal dementia (IBMPFD). ${ }^{9}$ Features of ALS were found in $10 \%$ of individuals, ${ }^{10}$ and VCP mutations have recently been linked to $1-2 \%$ of isolated familial ALS cases, which are associated with TDP-43 pathology. ${ }^{11}$ In addition, two mouse models of IBMPFD have been produced, both reproducing muscle, bone and brain pathology characteristic of the human disease, including TDP-43-positive inclusions. ${ }^{12,13}$ In one, nuclear clearance of TDP-43 was reported in $\sim 5 \%$ of spinal neurons. ${ }^{13}$

\footnotetext{
${ }^{1}$ Department of Neurology, University of California, Irvine, CA, USA; ${ }^{2}$ Department of Pediatrics, Division of Genetics and Metabolism, University of California, Irvine, CA, USA; ${ }^{3}$ Department of Orthopaedic Surgery, University of California, Irvine, CA, USA and ${ }^{4}$ Department of Anatomy \& Neurobiology, University of California, Irvine, CA, USA ${ }^{*}$ Corresponding author: JH Weiss, Department of Neurology, University of California, 2101 Gillespie Building, Irvine, CA 92697-4292, USA. Tel: +949 824 6774; Fax: +949 824 1668; E-mail: jweiss@uci.edu

or VE Kimonis, Department of Pediatrics, Division of Genetics and Metabolism, University of California, 101 The City Drive South, ZC4482, Orange, CA 92868, USA. Tel: +714 456 5791; Fax: +714 4565 330; E-mail: vkimonis@uci.edu

Keywords: motor neuron; SOD1; TDP-43; amyotrophic lateral sclerosis; animal models

Abbreviations: ALS, amyotrophic lateral sclerosis; AMPA, $\alpha$-amino-3-hydroxy-5-methyl-4-isoxazolepropionic acid; COX-IV, cytochrome oxidase subunit IV; EMG, electromyography; FTD, frontotemporal dementia; GFAP, glial fibrillary acidic protein; IBMPFD, Inclusion Body Myopathy associated with Paget's disease of bone and frontotemporal dementia; MN, motor neuron; PDB, Paget's disease of bone; SOD1, superoxide dismutase type 1; TDP-43, 43 kDa transactivation response (TAR) DNAbinding protein; UPS, ubiquitin-proteasome system; VCP, valosin-containing protein; WT, wild type

Received 05.4.12; revised 06.7.12; accepted 10.7.12; Edited by A Verkhratsky
} 
We have undertaken the first study to date examining the evolution of spinal cord pathology in a mutant VCP mouse model. Present studies use a novel heterozygous $\mathrm{R} 155 \mathrm{H}$ human VCP knock-in mouse model $\left(\mathrm{VCP}^{\mathrm{R} 155 \mathrm{H} /+}\right)$, in which the mutant gene is expressed in physiological patterns and levels. Clincially, these animals show mild progressive weakness, but do not develop rapidly progressive ALS-like disease. However, by 24 months, they have widespread denervation and neurogenic (as well as some myopathic) changes on electromyography (EMG), suggestive of a motor neuropathy/neuronopathy, and pathological examination shows progressive age-dependent MN degeneration. These animals also show age-dependent appearance of TDP-43labeled cytosolic inclusions in MNs, and astrogliosis. Mutant VCP knock-in animals provide a new model recapitulating key pathological features of ALS, which may yield insights into pathogenesis of both familial and sporadic forms of human disease.

\section{Results}

VCPR155H/+ heterozygous knock-in mice develop slowly progressive weakness. The Kimonis laboratory previously generated and characterized a heterozygote knock-in mouse with the most common human VCP mutation $(\mathrm{R} 155 \mathrm{H})$ expressed at physiological levels. ${ }^{12}$ Examination of brain, muscle, and bone pathology in this $\mathrm{VCP}^{\mathrm{R} 155 \mathrm{H} /+}$ mouse revealed many of the features of human IBMPFD disease, including the progressive cytoplasmic accumulation of TDP43 and ubiquitin-positive inclusions in muscle and the cerebral cortex. ${ }^{12}$ We have subsequently produced a slightly modified $\mathrm{VCP} \mathrm{R}^{\mathrm{R} 155 \mathrm{H} /+}$ knock-in mouse model (which is identical to the previously described model except for the lack of a Neomycin cassette) to assess and confirm the phenotype of the VCP mutant knock-in, without risk of interference from the Neo cassette. Like the Neo cassette containing strain, ${ }^{12}$ these Neo-free mice also express VCP at an endogenous level. Western blot studies of spinal cord tissue from these animals shows VCP levels to be indistinguishable from those in wild-type (WT) animals at both 7 and 18 months of age (Figure 1a).

These Neo-free heterozygotes, used in the present studies, have similar brain, muscle, and bone pathology as the Neo cassette containing heterozygotes, including the appearance of age-dependent pathological changes in muscle (with basophilic rimmed cracks and centrally located nuclei in muscle fibers, Figure 1b). The bone, brain, and muscle phenotype of these animals is more fully described in a separate publication. ${ }^{14}$ Furthermore, these mice appeared generally normal in growth and behavior. They showed mildly decreased weights after 24 months of age and mild progressive weakness from $\sim 9$ months of age (Figure 1ci and ii). Although their maximal lifespans are the same as WT mice (close to 30 months), their survival curves differ, with some $\mathrm{VCP} \mathrm{P}^{\mathrm{R} 155 \mathrm{H} /+}$ mice dying prematurely and survival time broadly distributed between $\sim 15$ and 30 months (Figure 1ciii).

Although these mice manifest slowly developing but extensive ALS-like spinal cord pathology (as described below), they do not develop a rapidly progressive ALS-like disease (as is seen in mutant SOD1-overexpressing models), and maintain generally normal appeareance and behavior throughout their lives. The absence of clinical ALS may be consistent with human VCP-linked disease, in which ALS only occurs in $\sim 10 \%$ of patients. The causes of the premature deaths in some of the $\mathrm{VCP} \mathrm{P}^{\mathrm{R} 155 \mathrm{H} /+}$ mice is not known, but may resemble causes of death in affected humans, many of whom die in their 40s-60s, often with cardiorespiratory failure. ${ }^{10}$

Notably, homozygosity of the $\mathrm{R} 155 \mathrm{H}$ mutation is lethal, with these animals dying by 21 days of age with indications of abnormalities in several systems including muscle, brain and spinal cord (the complex phenotype of these animals will be fully characterized in a separate publication).

EMG evidence of MN degeneration in aged $V C P^{R 155 H /+}$ mice. Needle EMG examination provides a valuable tool for the discrimination between neurogenic and myopathic causes of neuromuscular dysfunction. Neurogenic findings on EMG include fasciculation potentials and fibrillation potentials in the acute phase, as well as increased amplitude and duration of motor unit potentials with polyphasia and reduced recruitment. Myopathic changes include short duration, small amplitude polyphasic potentials with normal recruitment patterns.

EMG examination was carried out on four $\mathrm{VCP}^{\mathrm{R} 155 \mathrm{H} /+}$ animals and four WT littermates (see Materials and methods). Evidence of widespread acute denervation was seen in the $\mathrm{VCP}^{\mathrm{R} 155 \mathrm{H} /+}$ mice (average age $24.98 \pm 0.41$ months) but not in their WT littermates. These changes included varying degree of abnormal spontaneous activity in the form of fibrillation and fasciculation potentials, and distinct reduction in recruitment and interference patterns. Motor unit analysis was, however, complicated by the fact that both 'myopathic' (narrow duration, small amplitude) potentials and neurogenic (large amplitude, broad duration) potentials were seen. Firing rates were generally increased, suggestive of a neurogenic rather than myopathic pattern of activation (Figure 2a). Notably, these distinctive abnormalities were seen in almost all the muscles examined in the $\mathrm{VCP}^{\mathrm{R} 155 \mathrm{H} /+}$ mice, but were never seen in the WT mice (Figure 2b).

Age-dependent MN degeneration in $\mathrm{VCP} \mathrm{P}^{\mathrm{R} 155 \mathrm{H} /+}$ mice. MN degeneration was assessed in lumbar spinal cord sections from $\mathrm{VCP} \mathrm{P}^{\mathrm{R} 155 \mathrm{H} /+}$ and WT animals at various ages. MNs were labeled with toluidine blue, and immunocytochemically using an antibody to non-phosphorylated neurofilament epitopes, SMI-32, which strongly labels MNs as well as their neuritic processes. ${ }^{15}$ In WTs, virtually all MNs appeared healthy, with a small percentage showing mild atrophic changes in older animals (Figure $3 a$ and b). However, in the VCP $\mathrm{R}^{\mathrm{R} 155 \mathrm{H} /+}$ animals, there were clear age-dependent degenerative changes, which appeared to follow distinct pathways. Some MNs showed progressive cellular and nuclear constriction, others showed cytoplasmic vacuolar changes, and some showed nuclear enlargement and chromatin loss (Figure $3 a$ vii and viii). At late stages, MNs often appeared to be replaced by glial nodules (Figure 3a vii and viii, arrows). Surviving MNs were counted in SMI-32-labeled slices from VCP $\mathrm{V}^{\mathrm{R} 155 \mathrm{H} /+}$ and WT siblings (Figure $3 b$ ), from three age groups $(8 \pm 2,20 \pm 2,26 \pm 2$ months). By $\sim 20$ months, MN numbers in $\mathrm{VCP}^{\mathrm{R} 155 \mathrm{H} /+}$ mice 
a

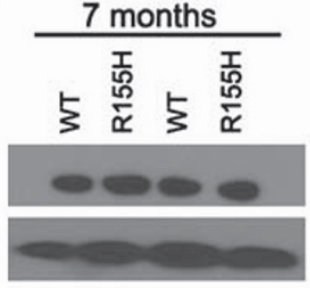

18 months

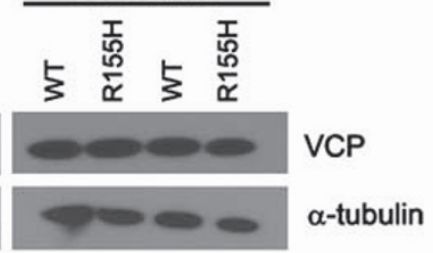

b

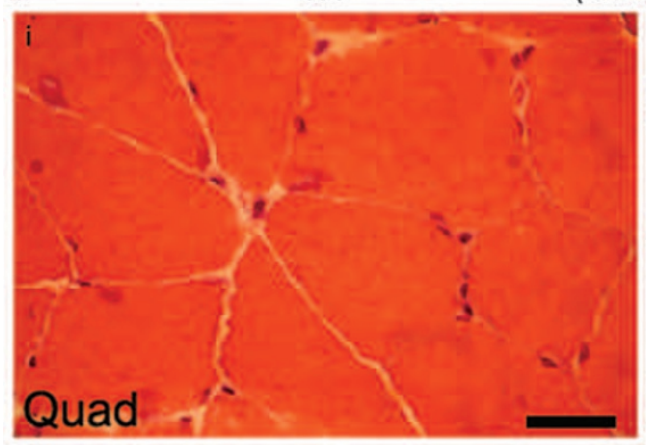

(20 months)
VCP ${ }^{\mathrm{R} 155 \mathrm{H} /+}$

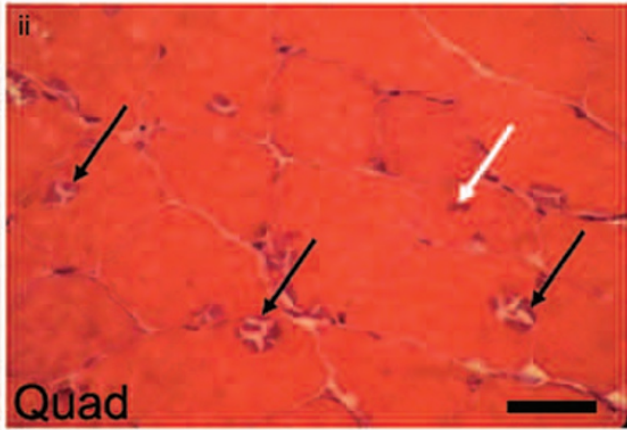

c

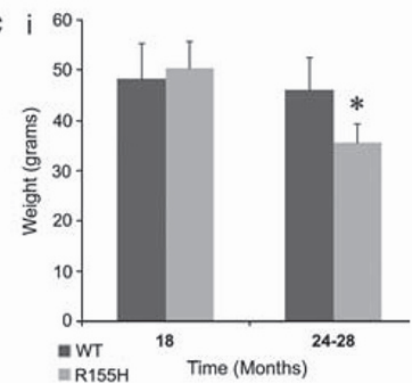

ii

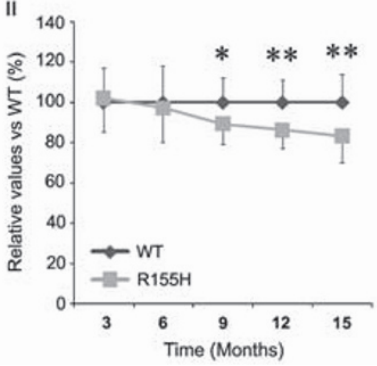

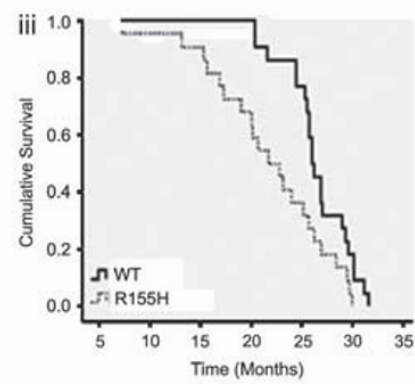

Figure 1 VCP expression levels, muscle pathology, mild weakness and modestly decreased lifespan in Neo cassette free VCP ${ }^{\mathrm{R} 155 \mathrm{H} /+}$ mice. (a) Western blots showing VCP expression in spinal cord of WT and VCP $P^{\mathrm{R} 155 \mathrm{H} /+}$ knock-in mice at 7 and 18 months of age. Note that WT and VCP ${ }^{\mathrm{R} 155 \mathrm{H} /+}$ mice show very similar levels of VCP at both 7 and 18 months of age (two animals of each genotype at each age). Alpha tubulin was used as a loading control. (b) Muscle pathology in VCPR155H/+ mice. Hematoxylin and eosin staining was carried out on quadriceps muscle from 20-month-old WT (left), and VCP ${ }^{\mathrm{R} 155 \mathrm{H} /+}$ knock-in (right) mice. Pathological features noted include variation in muscle fiber size, basophilic rimmed cracks (black arrows) and centrally located nucleii (white arrow). Bar $=50 \mu \mathrm{m}$. (c) Mild weight, strength and survival deficits in $\mathrm{VCP}^{\mathrm{R} 155 \mathrm{H} /+}$ mice. (i) Mildly decreased weight in VCP ${ }^{\mathrm{R} 155 \mathrm{H} /+}$ mice at $24-28$ months, but not at 18 months of age $\left(n=18\right.$ each WT and VCP ${ }^{\mathrm{R} 155 \mathrm{H} /+}$ mice at 18 months, $n=4$ each strain at $24-28$ months; ${ }^{*} P<0.05$ by two-tailed $t$-test). (ii) Mild progressive weakness in VCP ${ }^{R 155 H /+}$ mice. Grip strength was assessed using a Grip Strength Meter apparatus (TSE Systems Gmbh); for each measurement on each animal, the maximum force achieved among five repetitions was used. Note the mild but significant decrease in grip strength in $\mathrm{VCP} \mathrm{P}^{\mathrm{R} 155 \mathrm{H} /+}$ animals starting at 9 months of age. (14-16 WT animals and $12 \mathrm{VCP} \mathrm{P}^{\mathrm{R} 155 \mathrm{H} /+}$ animals were examined at each age. ${ }^{*}$ indicates significant difference by paired $t$-test at $P<0.01$; ${ }^{\star *} P<0.005$ ). (iii) Survival curve comparing the natural history of WT and $\mathrm{VCP} \mathrm{P}^{\mathrm{R} 155 \mathrm{H} /+}$ heterozygous mice. Mice were allowed to age until they died naturally. Note that although the maximal lifespan was close to 30 months in $\mathrm{VCP} \mathrm{P}^{\mathrm{R} 155 \mathrm{H} /+}$ as well as WT mice, some VCPR155H/+ mice died prematurely. $n=22$ $\mathrm{VCP}^{\mathrm{R} 155 \mathrm{H} /+}$ and 22 WT mice; $P<0.02$ by the log rank (Mantel-Cox) method

had decreased almost $50 \%$ (Figure 3c). Notably, at all ages examined, neurodegenerative changes were far less in the dorsal horn (Figure 3a, bottom panels).

Age-dependent TDP-43 pathology and mitochondrial aggregation in $\mathrm{VCP}^{\mathrm{R} 155 \mathrm{H} /+}$ mice. Western blots were carried out to assess levels of TDP-43 in spinal cord. Interestingly, TDP-43 levels were similar in WT and $\mathrm{VCP} \mathrm{R}^{\mathrm{R} 155 \mathrm{H} /+}$ mice at 7 months of age, but were markedly increased in $\mathrm{VCP} \mathrm{P}^{\mathrm{R} 155 \mathrm{H} /+}$ mice at 18 months (Figure 4a). Immunostains were carried out to assess the occurrence of TDP-43 containing cytosolic aggregates in MNs. In young WT animals, staining was either absent, was nuclear, or appeared diffusely in the cytosol (Figure $4 \mathrm{~b}$ i and ii). With increasing age, a mild degree of cytosolic aggregation was noted in some MNs (Figures $4 \mathrm{~b}$ iii and c). This agedependent appearance of TDP-43 pathology in WT animals may be compatible with recent observations of TDP-43 pathology in brains of $29 \%$ of non-diseased humans over $65 .{ }^{16}$ In contrast, in the $\mathrm{VCP} \mathrm{P}^{\mathrm{R} 155 \mathrm{H} /+}$ mice, there was a far greater tendency for TDP-43 to appear in dense cytosolic aggregates, which increased prominently with age (Figure $4 \mathrm{~b}$ iv, v and vi). Quantification of the degree of cytosolic TDP-43 aggregation (see 'Quantification of histopathological changes' under Materials and Methods), confirmed the significantly greater age-dependent cytosolic TDP-43 aggregation in the mutant animals (Figure 4c). Interestingly, in the homozygous $\mathrm{VCP} \mathrm{P}^{\mathrm{R} 155 \mathrm{H} / \mathrm{R} 155 \mathrm{H}}$ animals, in which only mutant VCP is present and which generally die with severe weakness and multiple organ involvement by 3 weeks of 


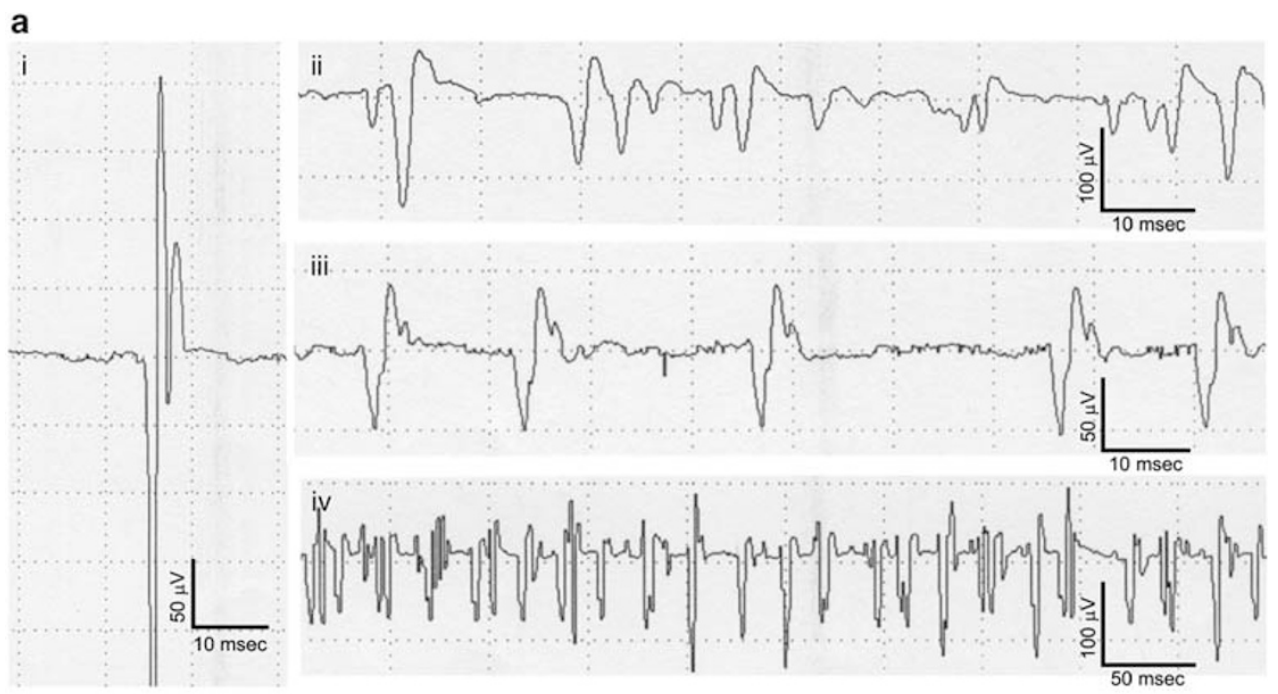

b

\begin{tabular}{|c|c|c|c|c|c|c|c|}
\hline Animal No & Type & Fasciculations & Fibrillations & $\begin{array}{c}\text { Mixed } \\
\text { MUP } \\
\text { Amplitude }\end{array}$ & $\begin{array}{c}\text { Reduced } \\
\text { Motor Unit } \\
\text { Recruitment }\end{array}$ & $\begin{array}{c}\text { Reduced } \\
\text { Motor Unit } \\
\text { Interference }\end{array}$ & $\begin{array}{c}\text { Increased } \\
\text { Motor Unit } \\
\text { Firing Rate }\end{array}$ \\
\hline \hline 284 & Wildtype & $0 / 7$ & $0 / 7$ & $0 / 7$ & $0 / 7$ & $0 / 7$ & $0 / 7$ \\
\hline 838 & Wildtype & $0 / 7$ & $0 / 7$ & $0 / 7$ & $0 / 7$ & $0 / 7$ & $0 / 7$ \\
\hline 839 & Wildtype & $0 / 7$ & $0 / 7$ & $0 / 7$ & $0 / 7$ & $0 / 7$ & $0 / 7$ \\
\hline 840 & Wildtype & $0 / 7$ & $0 / 7$ & $0 / 7$ & $0 / 7$ & $0 / 7$ & $0 / 7$ \\
\hline & & & & & & & \\
\hline 274 & $\mathrm{R} 155 \mathrm{H} /+$ & $5 / 7$ & $7 / 7$ & $7 / 7$ & $7 / 7$ & $7 / 7$ & $7 / 7$ \\
\hline 328 & $\mathrm{R} 155 \mathrm{H} /+$ & $5 / 7$ & $3 / 7$ & $7 / 7$ & $7 / 7$ & $7 / 7$ & $7 / 7$ \\
\hline 400 & $\mathrm{R} 155 \mathrm{H} /+$ & $2 / 7$ & $3 / 7$ & $7 / 7$ & $7 / 7$ & $7 / 7$ & $7 / 7$ \\
\hline 412 & $\mathrm{R} 155 \mathrm{H} /+$ & $6 / 7$ & $6 / 7$ & $7 / 7$ & $7 / 7$ & $7 / 7$ & $7 / 7$ \\
\hline
\end{tabular}

Figure 2 EMG evidence of muscle denervation in $\mathrm{VCP}^{\mathrm{R} 155 \mathrm{H} /+}$ mice. EMG studies were carried out on four $\mathrm{VCP} \mathrm{P}^{\mathrm{R} 155 \mathrm{H} /+}$ animals (average age $24.98 \pm 0.41 \mathrm{months}$ ), in comparison with four WT littermates. (a) Traces show representative pathological changes, which were seen only in the VCP ${ }^{\mathrm{R} 155 \mathrm{H} /+}$ animals. (i) Fasciculation potential; (ii) fibrillation potentials; (iii) reduced motor unit recruitment. This is a neurogenic recruitment pattern. Firing frequency in these animals was increased at $50 \mathrm{~Hz}$. (iv) $\mathrm{Co}$-existing neurogenic and myopathic potentials. Motor units exhibit mixed morphology with small amplitude, polyphasic potentials, suggestive of a myogenic disturbance. However, recruitment frequencies are decreased, suggesting a neurogenic pattern. (b) Tabular chart showing frequency of various abnormalities seen on EMG from the sampling of seven muscles in each animal. Note frequent abnormalities in $\mathrm{VCP} \mathrm{P}^{\mathrm{1} 155 \mathrm{H} /+}$ animals and absence of abnormalities in WT mice (MUP, motor unit potential)

age, advanced TDP-43 pathology was evident in MNs of 10-day-old animals, an age at which $\mathrm{VCP}^{\mathrm{R} 155 \mathrm{H} /+}$ mice showed little TDP-43 pathology (Figure $4 \mathrm{~b}$ vii).

We also carried out double immunofluorescence stains for TDP-43 along with the mitochondrial marker, COX-IV. In young WT and $\mathrm{VCP}^{\mathrm{R} 155 \mathrm{H} /+}$ animals, COX-IV labeling was diffuse and speckled, as expected for mitochondria, and TDP43 labeling was faint and nuclear or diffuse cytosolic (as described above). In aged ( $\sim 18$ month) WT animals, mitochondria were still diffusely distributed, but there was some minimal aggregation noted, which co-localized with areas of slight TDP-43 aggregation (Figure $5 \mathrm{a} i$ and ii). However, in the aged VCP ${ }^{\mathrm{R} 155 \mathrm{H} /+}$ animals, COX-IV labeling was densely aggregated and co-localized strongly with TDP43 (Figure $5 \mathrm{a}$ iii and iv). Examination of all MNs in sets of agematched sections revealed little COX-IV aggregation up to 8 months in either WT or VCP $\mathrm{R}^{\mathrm{R} 155 \mathrm{H} /+}$ animals, but substantial co-aggregation of COX-IV and TDP-43 by 18 months only in the $\mathrm{VCP} \mathrm{P}^{\mathrm{R} 155 \mathrm{H} /+}$ animals, with much milder age-dependent co-aggregation seen in WT animals (Figure 5b).
To further address the pathological similarities between the VCP $\mathrm{R}^{\mathrm{R} 155 \mathrm{H} /+}$ animals and diverse forms of human ALS, we carried out immunostains for ubiquitin (Figure $5 \mathrm{c}$ ) as well as for the autophagy related protein, SQSTM1/P-62 (Figure 5d), both of which are prominent constituents of cytosolic MN aggregates in most human ALS cases. ${ }^{17}$ Labeling with either marker revealed appearance of cytosolic aggregates similar to that seen with TDP-43, with far greater age-dependent cytosolic aggregation in the VCP $\mathrm{R}^{\mathrm{R} 155 \mathrm{H} /+}$ animals than in WT animals.

\section{Age-dependent astrogliosis and 3-nitrotyrosine labeling} in heterozygous $\mathbf{R} 155 \mathrm{H}$ mice. Previous reports have indicated progressive reactive astrogliosis in mutant SOD1 as well as TDP-43 mouse models of ALS. ${ }^{7,18}$ Similarly, we see a dramatic age-dependent increase in GFAP labeling in $\mathrm{VCP}^{\mathrm{R} 155 \mathrm{H} /+}$ animals, most prominent in ventral horn (Figure 6a and $\mathrm{c} \mathrm{i}$ ).

Paralleling this increased astrogliosis, we also note increases in 3-nitrotyrosine (3-NT) labeling, both within 
a
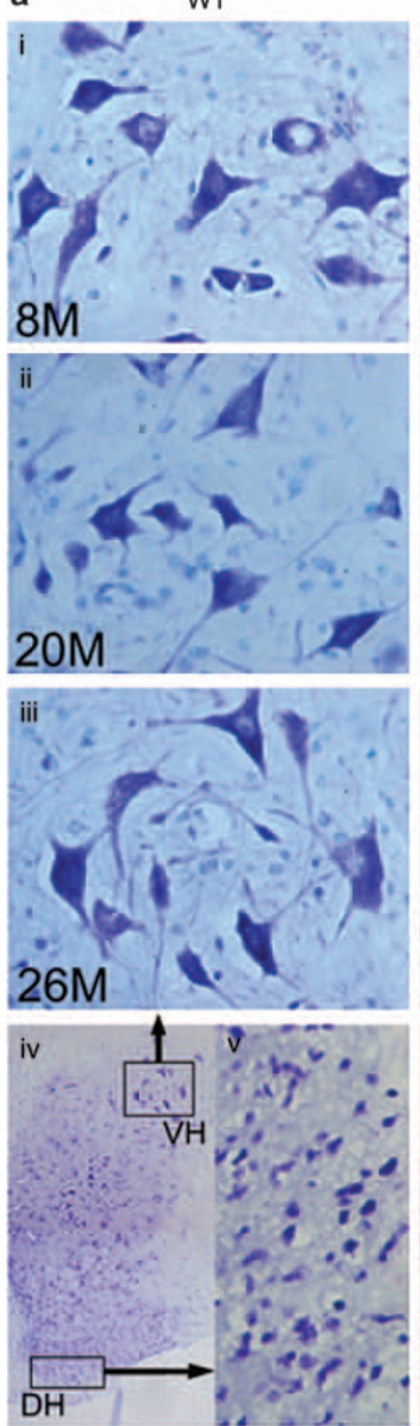

VCP ${ }^{\mathrm{R} 155 \mathrm{H} / *}$
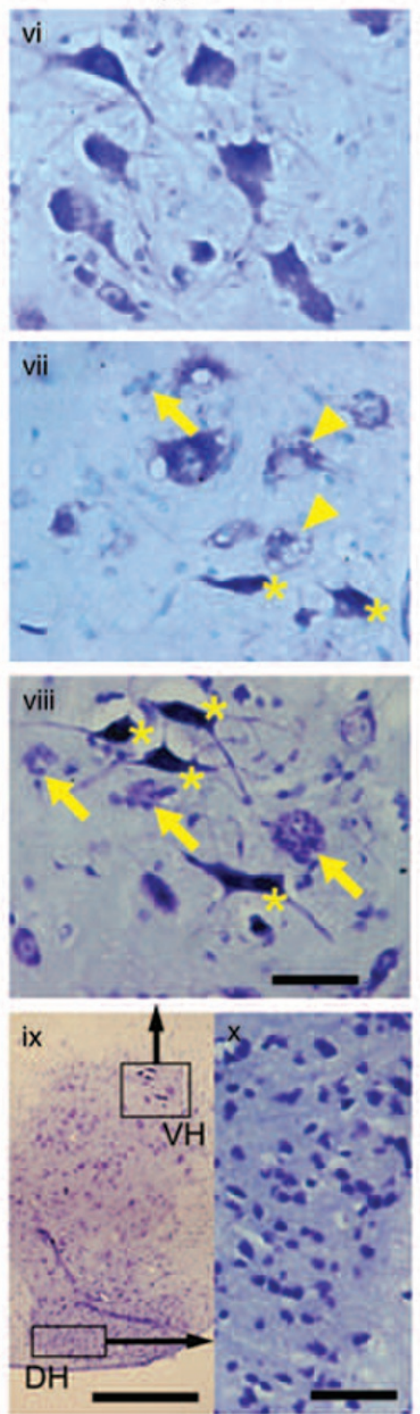

b
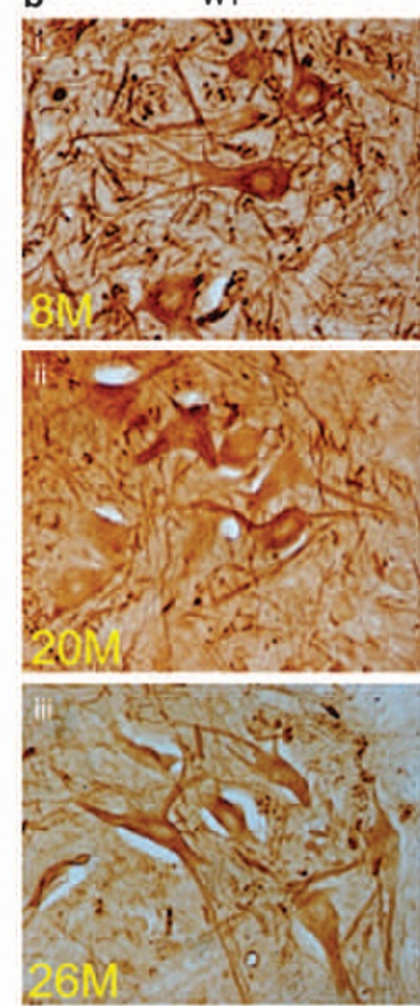

C

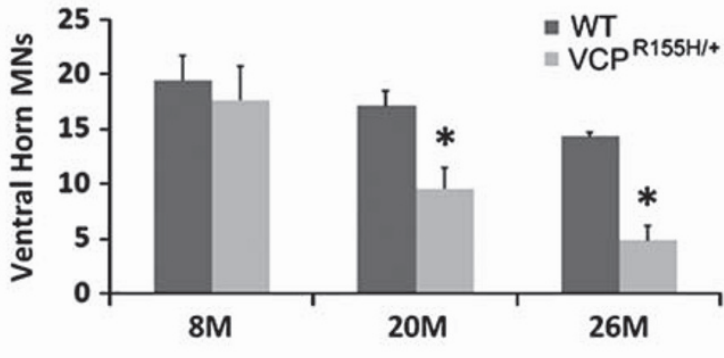

Figure 3 Progressive age-dependent degenerative changes and loss of ventral horn MNs from heterozygous VCP knock-in $\left(\mathrm{VCP}^{\mathrm{R} 155 \mathrm{H} /+}\right)$ mice. (a) Age-dependent degenerative changes in ventral horn MNs VCP ${ }^{\mathrm{R} 155 \mathrm{H} /+}$ mice. Lumbar sections were stained with toluidine blue. Images show representative fields $(400 \times)$ from ventral horn of WT and sibling VCP ${ }^{R 155 H /+}$ mice at the indicated ages ( \pm 2 months). In the WTs, virtually all MNs appeared healthy, with mild atrophic changes noted in a small number of the older MNs. In contrast, in VCP $\mathrm{R}^{155 \mathrm{H} /+}$ animals, clear age-dependent degenerative changes are seen (panels vii and viii) with eccentric nuclei, fragmentation of dendrites, and some MNs showing cellular and nuclear constriction (stars), and others showing prominent swelling and vacuolar changes in cytoplasm (arrowheads). In some cases, degenerated MNs were replaced by glial nodules (arrows). Bottom panels (iv and ix) show low power views from 26-month-old spinal cords, with regions from ventral horn $(\mathrm{VH})$ and dorsal horn $(\mathrm{DH})$ highlighted. Arrows indicate high power views of regions indicated. Note the relative preservation of neuronal morphology in the $\mathrm{DH}$ region, despite extensive degenerative changes in the $\mathrm{VH}$ region of the 26 month $\mathrm{VCP} \mathrm{P}^{\mathrm{R} 155 \mathrm{H} /+}$ mouse (panels viii, ix, and $\mathrm{x}$ ). Comparative examination of $\mathrm{VH}$ and $\mathrm{DH}$ regions from $>40$ slices from $26 \pm 2$-month-old WT and VCP $\mathrm{P}^{\mathrm{R} 155 \mathrm{H} /+}$ mice revealed similar condition of $\mathrm{VH}$ and DH neurons in all WT's but distinctly greater degenerative changes in VH MNs compared to $\mathrm{DH}$ regions in all slices from $\mathrm{VCP}^{\mathrm{R} 155 \mathrm{H} /+}$ mice. Bar $=500 \mu \mathrm{m}$ (low power panels); $50 \mu \mathrm{m}$ (all other panels). (b) Age-dependent loss of ventral horn MNs in $\mathrm{VCP}^{\mathrm{R} 155 \mathrm{H} /+}$ mice. Lumbar sections were immunostained for the non-phosphoryylated neurofilament marker, SMI-32. Images show representative fields $(400 \times)$ from ventral horn of WT and sibling VCP ${ }^{R 155 H /+}$ mice at the indicated ages ( \pm 2 months). Note the age-dependent atrophy and loss of MNs in the VCP R155H/+ animals. Bar $=50 \mu \mathrm{m}$. (c) Quantification of MN cell loss. Surviving MNs were counted in SMI-32 immunostained slices from each condition. Values represent mean number of surviving ventral horn MNs per section (containing two ventral horns), as assessed under direct microscopic examination. Each data point reflects counts from 3-7 animals (for SMI-32); all ventral horn MNs were counted in each of 10-15 slices for each animal. Note the modest age-dependent MN loss in WTs in contrast to the marked loss in the VCP ${ }^{\mathrm{R} 155 \mathrm{H} /+}$ mice. * indicates difference from WT animals at the same age by two-tailed $t$-test $(P<0.025)$

and between ventral horn MNs. Unlike the astrogliosis, this 3-NT labeling was most prominent at $\sim 20$ months, decreasing at advanced ages when many MNs had degenerated. As noted in our studies of mutant SOD1 animals, ${ }^{19,20}$ the 3-NT labeling was often particularly strong near MN somata, falling off sharply with distance, possibly consistent with a role of ROS generated within MNs (Figure $6 \mathrm{~b}$ and $\mathrm{c}$ ii). 


\section{Discussion}

Summary of findings. $\mathrm{VCP} \mathrm{P}^{\mathrm{R} 155 \mathrm{H} /+}$ mice display distinct age-dependent $\mathrm{MN}$ degeneration, with accompanying neurogenic changes on EMG testing. Interestingly, these mice have modestly decreased lifespans, with substantial MN loss only in elderly animals. Thus, in contrast to the relatively abrupt onset and rapid progression of $\mathrm{MN}$
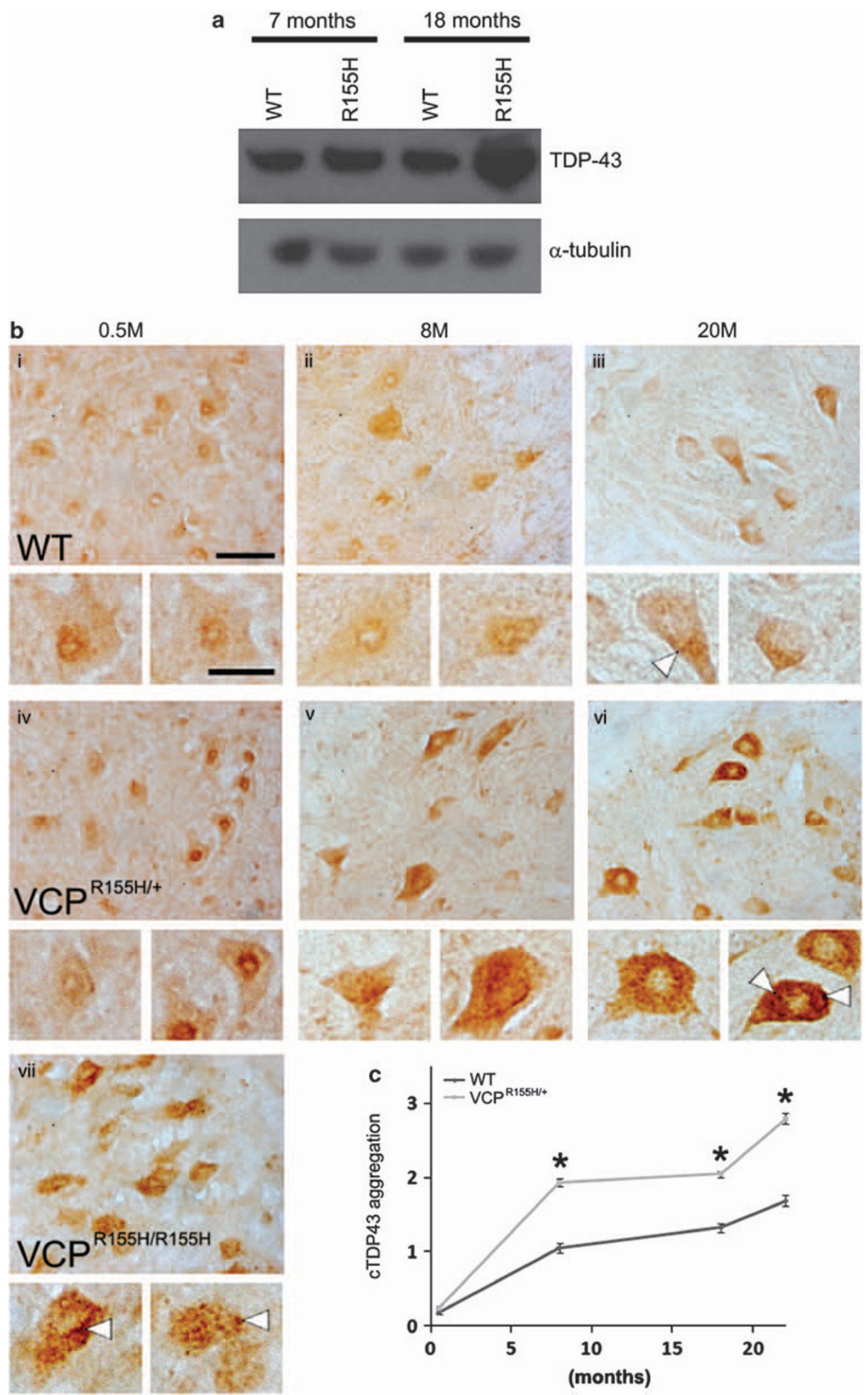
degeneration seen in mutant SOD1 overexpressing animal models, these knock-in animals, which express a mutant human gene in physiological patterns, show slowly progressive MN damage, possibly modeling the slow evolution of spinal cord pathology preceding the onset of rapidly progressive clinical ALS in subsets of patients with mutations in VCP or other ALS risk enhancing genes of incomplete penetrance. It is intriguing that with advancing age, these animals develop fairly extensive (>50\%) MNs loss with minimal symptoms, possibly reflecting the slow evolution of pathology, providing time for compensatory mechanisms to maintain adequate motor function.

In addition to $\mathrm{MN}$ loss, these animals also display other characteristic features of human spinal cord ALS pathology, including the appearance of TDP-43 containing cytosolic inclusions, evidence of mitochondrial aggregation, progressive astrogliosis and indices of oxidative damage in affected ventral horn tissues. Of note, examination of findings in agematched WT animals revealed that virtually all the pathological findings were not exclusive to the mutant animals, but occurred, albeit far more slowly and to a milder degree, in WTs, raising the possibility that an effect of the mutant VCP gene may be to accelerate certain processes that occur normally with aging. The presence of advanced cytosolic TDP-43 inclusions in very young homozygous $\mathrm{VCP}^{\mathrm{R} 155 \mathrm{H} / \mathrm{R} 155 \mathrm{H}}$ animals may be consistent with this idea.

Relevance to human disease. Although the development of mutant SOD1 animal models of ALS provided a major advance in the study of disease processes, there is uncertainty regarding the relevance of these models to most human ALS. Subsequent characterization of the linkage between TDP-43 and FUS with both familial and sporadic forms of $A L S^{5,6}$ has led to the recent development of novel TDP-43 based animal models. In addition, as TDP-43 and FUS are both associated with FTD as well as with ALS, these models may prove more broadly relevant to mechanisms of neurodegenerative disease. However, most TDP-43-based animal models fail to show characteristic TDP-43 containing cytosolic aggregates, ${ }^{7}$ raising questions as to how well they recapitulate key events of human disease.

It is intriguing that the disease spectrum caused by VCP mutations similarly includes both ALS and FTD and that TDP43 pathology occurs prominently in VCP linked disease. .,11-13 $^{9}$ Whereas TDP-43 and FUS are both thought to be primarily nuclear RNA/DNA-binding genes involved in aspects of RNA metabolism, the unrelated VCP protein (also known as p97) belongs to the family of type II ATPase associated with a variety of cellular activities (AAA). Although the relevant mechanism in disease is uncertain, among its many functions, it appears to have important roles in the delivery of proteins from the ER to the cytosol, regulation of ubiquitination, ${ }^{21}$ and the maturation of autophagosomes into autolysosomes, ${ }^{22}$ and thus may be crucial to the normal function of ubiquitinproteasome-dependent proteolysis (UPS) and autophagy. Suggesting interactions between VCP and TDP-43-dependent mechanisms, either mutant VCP or autophagic inhibition resulted in cytosolic TDP-43 accumulation. ${ }^{22}$

Other recent studies lend further support to the idea that defects in protein clearance mechanisms (proteolysis or autophagy) may have integral roles in ALS. Mutations in the gene UBQLN2, which encodes a ubiquitin-like protein, ubiquilin 2, involved in protein degradation through the UPS, were recently found to be linked to forms of dominantly inherited, X-linked ALS and ALS/dementia. ${ }^{23}$ Similarly, mutations in optineurin ${ }^{24}$ and in SQSTM1 (which encodes the protein p62), ${ }^{25}$ both of which were previously linked to Paget's disease of bone and have roles in UPS/autophagy pathways, were recently found to be linked to rare familial or sporadic forms of ALS. Interestingly, ubiquilin 2, optineurin, and SQSTM1 are major components of the inclusions seen in most familial and sporadic ALS patients, often along with ubiquitin and TDP-43, even the absence of mutations in these genes. ${ }^{17,23,24}$ Thus, there appears to be a common final pathway for multiple forms of familial and sporadic ALS, wherein cytosolic accumulation of aggregated proteins, whether via a primary enhancement of aggregate formation or via defects in autophagy or the UPS, creates an environment that promotes neurodegeneration.

\section{Emerging clues to common mechanisms of selective MN degeneration in diverse forms of ALS. Comparison of the} evolution of pathological changes between SOD1, TDP-43 and VCP models of ALS provide hints of other commonalities. First, in addition to MN degeneration, SOD1 and TDP43 based models, like the present VCP mutant model, show prominent and progressive astrogliosis in ventral horn over the course of the disease, ${ }^{7,26}$ highlighting the likely contributions of neighboring astrocytes to the pathogenesis of $\mathrm{MN}$ degeneration in ALS. One consequence of astrocyte dysfunction may be loss of their glutamate transport capacity, which has been widely described in ALS and may underlie glutamate receptor mediated (excitotoxic) contributions to MN injury. ${ }^{1}$ In addition, all three models show evidence for the involvement of mitochondria in cytosolic aggregates, ${ }^{2,27,28}$ consistent with prominent roles of mitochondrial dysfunction in ALS.

Figure 4 Age-dependent increases in total spinal cord TDP-43 and its appearance in cytosolic inclusions in ventral horn MNs of VCP ${ }^{\mathrm{R} 155 \mathrm{H} /+}$ mice. (a) Western blots showing TDP-43 expression in spinal cord of WT and VCP ${ }^{\mathrm{R} 155 \mathrm{H} /+}$ knock-in mice at 7 and 18 months of age. Note that WT and VCP ${ }^{\mathrm{R} 155 \mathrm{H} /+}$ mice show very similar levels of TDP-43 at 7 months of age, whereas TDP-43 levels were markedly increased in the VCP ${ }^{\mathrm{R} 155 \mathrm{H} /}+$ spinal cord at 18 months. Alpha tubulin was used as a loading control. (b) Immunocytochemical assessment of cytosolic TDP-43 aggregation as a function of age-representative photomicrographs. Lumbar sections were immunostained for TDP43 and photographed $(400 \times)$. Representative fields are shown from ventral horn of WT (i, ii, and iii) and sibling VCP ${ }^{\mathrm{R} 155 \mathrm{H} /+}$ mice (iv, v, and vi) at the indicated ages ( \pm 2 months). In WT animals, faint and generally cytosolic or nuclear labeling was generally seen at young ages, with more prominent but generally still diffuse staining seen by 20 months. In the $\mathrm{VCP} \mathrm{R}^{\mathrm{R} 155 \mathrm{H} /+}$ animals, cytosolic TDP-43 labeling was both stronger, and far more prone to appear as discrete inclusions or aggregates with increasing age (arrowheads). By way of comparison, we also show stains from young ( 0.5 months) homozygous VCP ${ }^{R 155 H / R 155 H}$ animals (vii). Note the markedly accelerated appearance of strong cytosolic TDP-43 aggregation in MN from these young mice (arrowheads). Bar $=50$ or $25 \mu \mathrm{m}$ (detail). (c) Quantification of cytosolic TDP-43 aggregation. Each MN in examined sections was rated for cytosolic TDP-43 aggregation according to a five point scale as described (see Materials and methods). Each data point represents all MNs $(>160)$ present in 5-10 ventral horn micrographs from each of 2-5 animals. * indicates difference from WT animals at the same age by two-tailed $t$-test $(P<0.001)$ 
a
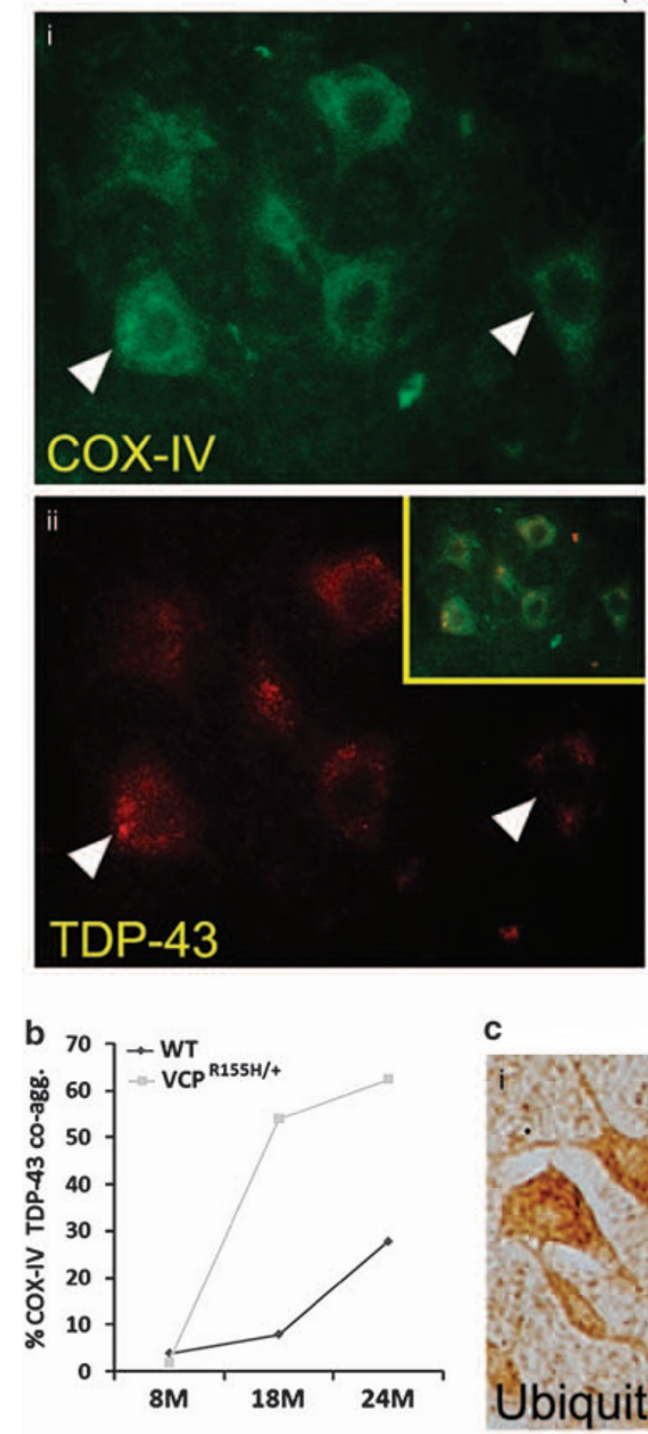

c
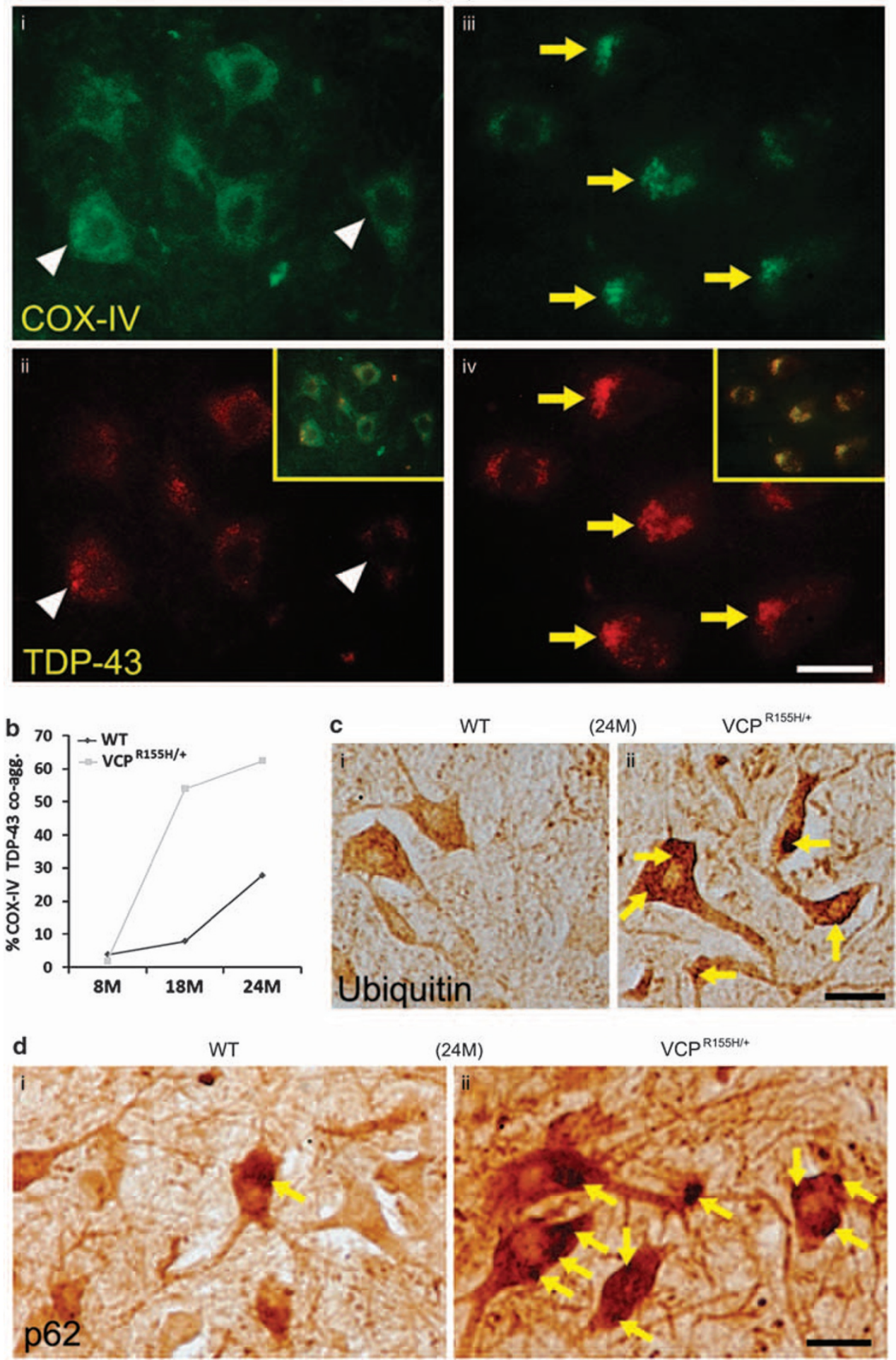

(24M)

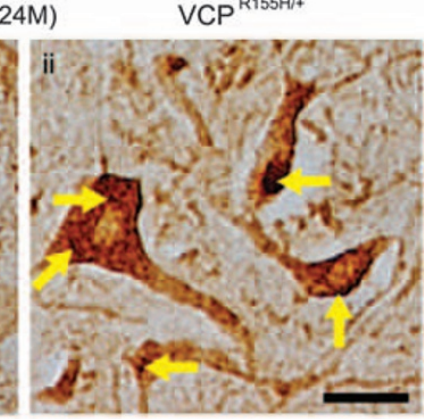

$\mathrm{VCP}^{\mathrm{R} 155 \mathrm{H} /+}$

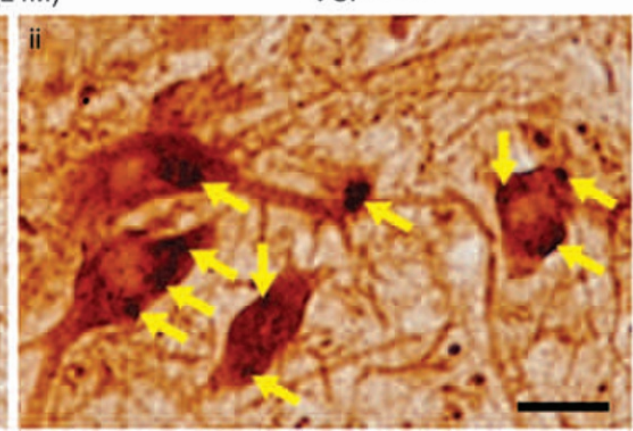

Figure 5 Colocalization of mitochondrial aggregates with TDP-43, and occurrence of ubiquitin and SQSTM1/p62 aggregates in aging VCP ${ }^{\mathrm{R} 155 \mathrm{H} /+} \mathrm{MNs}$. (a) Representative images. Slices were double fluorescence immunostained for the mitochondrial marker, COX-IV (top) and TDP-43 (bottom) (400 $\times$ ); inserts show overlay. Note in the 18-month-old WT animals, the COX-IV labeling is speckled and distributed throughout the cytoplasm. TDP-43 labeling shows mild early aggregation in a small number of MNs, that co-localizes with some early mitochondrial aggregation (arrowheads). In contrast, in age-matched VCP ${ }^{\mathrm{R} 155 \mathrm{H}+}+$ animals, the COX-IV labeling is highly aggregated and colocalizes with TDP-43 (arrows). Bar $=25 \mu \mathrm{m}$. (b) Quantification of COX-IV and TDP-43 co-aggregation. Graph shows the \% of examined MNs containing COX-IV and TDP-43 co-aggregation at each age (each point based on examination of $>40 \mathrm{MNs}$ ). Note the paucity of co-aggregation at 8 months in all animals, and the sharp increase of co-aggregation in the VCP ${ }^{R 155 H /+}$ mice by 18 months. (c and d): Ubiquitin (c) and SQSTM1/ p62 (d) labeling (24-month-old animals) revealed similar patterns of age-dependent appearance of cytosolic aggregates as seen for TDP-43. Arrows denote aggregates in $\mathrm{VCP}^{\mathrm{R} 155 \mathrm{H} /+} \mathrm{MNs}$. Bar $=25 \mu \mathrm{m}$ 
a
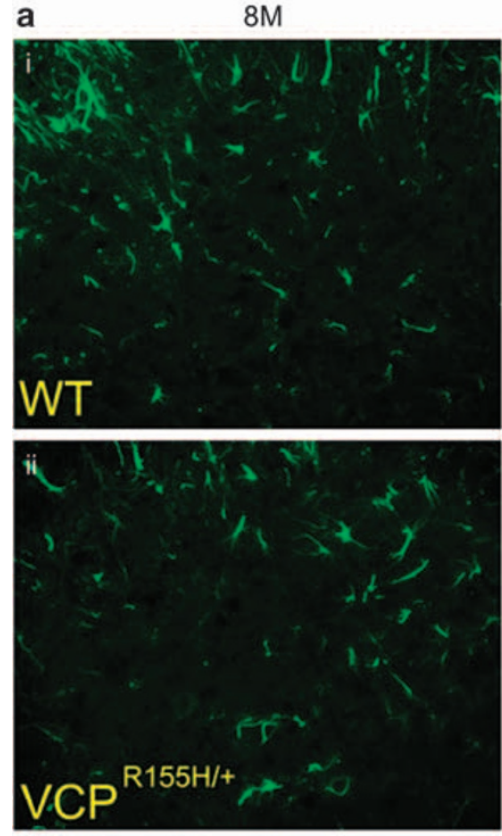

b
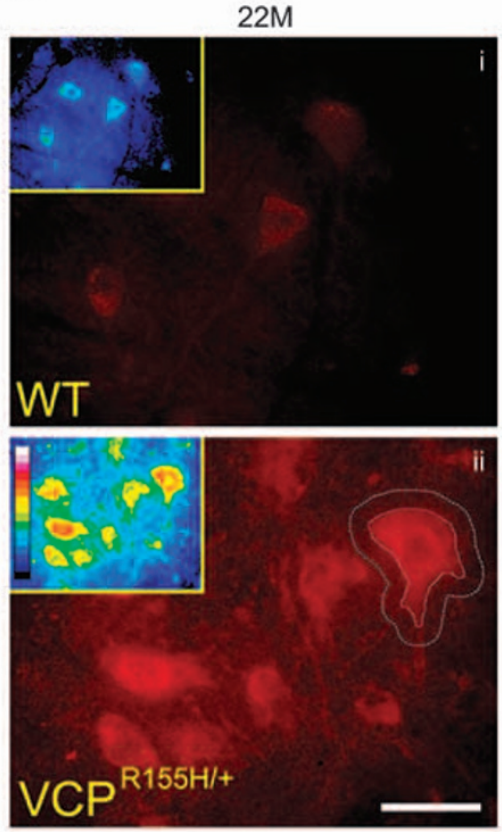
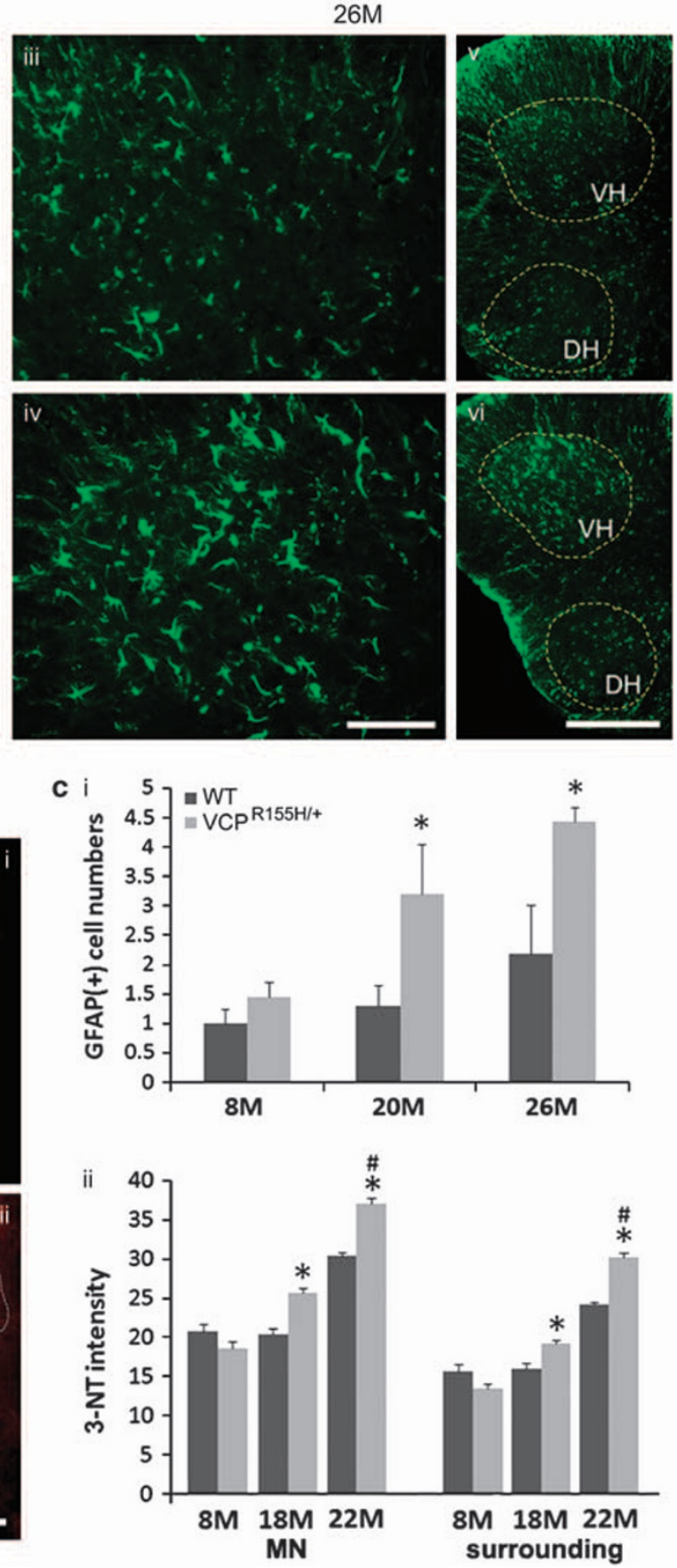

Figure 6 Progressive astrogliosis and increased 3-NT labeling in ventral horn of $\mathrm{VCP} \mathrm{P}^{\mathrm{R} 155 \mathrm{H} /+}$ mice. (a) Representative images of GFAP labeled slices. Lumbar sections were immunostained for GFAP and the ventral horns photographed under fluorescence $(200 \times)$. Note the marked increase in reactive astrocytes in VCP ${ }^{\mathrm{R} 155 \mathrm{H} /+}$ mice at 26 months (iv). Low magnification images of the hemi-spinal cord show the greater degree of astrogliosis in the ventral horn (VH) compared with the dorsal horn (DH) of the $\mathrm{VCP}^{\mathrm{R} 155 \mathrm{H} /+}$ mice (vi). Bar $=50 \mu \mathrm{m}$ (high power); $400 \mu \mathrm{m}$ (low power). (b) Representative images of 3-NT labeled slices. Lumber slices from 22-month-old WT and VCP $155 \mathrm{H} /$ ${ }^{+}$mice were immunostained for 3-NT, and photographed under immunofluorescence. Inserts show pseudocolor (8 bit) representation of fluorescence, in order to highlight the gradient in labeling intensity. Note the moderate labeling of WT MNs, but the markedly increased intensity of labeling not only in MNs of the VCP ${ }^{\mathrm{R} 155 \mathrm{H} /+}$ mice, but also in the neuropil surrounding and between MNs. (Dotted lines show representative regions marked for one MN, as was used for fluorescence quantification, below). Note that the region of increased 3-NT labeling between ventral horn MNs in the $\mathrm{VCP}^{\mathrm{R} 155 \mathrm{H} /+}$ mice may correspond generally to the region of increased ventral horn astrogliosis (see a, panels iv and vi above) in these animals. Bar $=50 \mu \mathrm{m}$. (c): Quantification of GFAP and 3-NT labeling. (i) GFAP immunoreactive astrocytes were counted from lumbar ventral horns of WT and VCP ${ }^{R 155 H /+}$ mice of the indicated ages. Each data point reflects counts from 3-5 animals; for each animal, all GFAP labeled astrocytes were counted from $200 \times$ ventral horn microscope fields from five sections. Note the marked age-dependent increase in numbers of reactive astrocytes in the VCPR155H/+ animals. ${ }^{*}$ indicates difference from WT animals at the same age by two-tailed $t$-test $(P<0.025)$. (ii) 3-NT labeling intensity was assessed in MNs, and in $10 \mu \mathrm{m}$ wide zones surrounding MNs, in WT and $\mathrm{VCP} \mathrm{P}^{\mathrm{R} 15 \mathrm{H} /}+$ mice as indicated. Each data point represents all MNs $(>75)$ present in 5-10 ventral horn micrographs from each of 2-5 animals. Note the agedependent increase in 3-NT labeling in WT mice, and the greater increase in VCP ${ }^{\mathrm{R} 155 \mathrm{H} /+}$ mice, both within the MNs (MN) and in the neuropil surrounding them (surrounding). * indicates difference from WT animals at the same age by two-tailed $t$-test $(P<0.001)$; $\#$ indicates difference from 18-month-old $\mathrm{VCP}$ R155H/+ mice $(P<0.001)$ 
A central question in the study of ALS pathogenesis is thus how a range of perturbations, likely reflecting combinations of genetic and environmental factors, may trigger a convergent phenotype with selective MN loss and surrounding astrogliosis. Possible clues to the selectivity of MN loss may be provided by studies examining factors underlying their high vulnerability to excitotoxic injury. Specifically, susceptible MNs possess large numbers of unusual $\mathrm{Ca}^{2+}$ permeable AMPA channels, ${ }^{15,29}$ yet have little ability to buffer cytosolic $\mathrm{Ca}^{2+}$ rises, ${ }^{30,31}$ such that they may be unusually prone to mitochondrial $\mathrm{Ca}^{2+}$ loading and consequent oxidative stress. $^{19,32}$

Excessive oxidative stress could contribute to the oxidation and aggregation of various proteins. Indeed, in the case of SOD1-linked disease, oxidative stress promotes the formation of insoluble SOD1 multimers in affected spinal cord tissue. ${ }^{33,34}$ Interestingly, oxidative stress has also recently been reported to promote the aggregation of TDP-43 and its recruitment into stress granules. ${ }^{35,36}$ Other recent studies suggest that with both $\mathrm{SOD} 1^{37,38}$ and TDP- $43,{ }^{39,40}$ the aggregates may mediate injury in large part via interactions with mitochondria.

Present findings of mitochondrial aggregation in the VCP model (analogous to that previously reported in SOD1 and TDP-43 models), along with evidence of increased oxidative stress (3-NT labeling) within and surrounding the MNs are also compatible with a mechanism wherein disruption of mitochondrial function, perhaps reflecting a combination of retention of dysfunctional mitochondria due to defects in autophagy/mitophagy and deleterious interactions with misfolded proteins, results in further oxidative stress, more protein aggregations and propagation of a disese process in which mitochondrial dysfunction, oxidative stress and protein aggregation are all intimitely involved. Oxidative stress in and around MNs could also contribute to the activation (and likely dysfunction) of ventral horn astrocytes seen in each of the three ALS models (SOD1, TDP-43 and VCP). ${ }^{20,41}$

\section{Conclusions}

Present studies extend the range of animal models available to study mechanisms underlying pathogenesis in ALS. The pathological commonalities between human ALS and the three animal models of genetic forms discussed (SOD1, TDP43 and VCP) are striking, in that they all show, in addition to preferential MN loss, the appearance of aggregates in $\mathrm{MNs}$, evidence of mitochondrial dysfunction and/or oxidative tissue damage, and pronounced astrogliosis in the ventral horn. Thus, it appears that mutations in these three completely unrelated genes can trigger a cascade of events resulting in a relatively characteristic pathological phenotype. A key aim of ongoing studies is thus to elucidate what ties these distinct forms of disease together and explains the convergent phenotype despite distinct 'causes'. It is likely that the convergent phenotype reflects attributes of the MNs themselves and the nature of their interactions with surrounding cells like astrocytes. We suggest a possible factor: that MNs, in part because of their complement of excitatory receptors and $\mathrm{Ca}^{2+}$ handling characteristics, are unusually prone to oxidative stress, which may promote aggregation and misfolding of proteins. Primary defects in UPS/autophagy pathways (as may occur with VCP, UBQLN2, SQSTM1, or optineutin mutations) may similarly promote aggregate formation. The aggregates may disrupt mitochondrial function, causing more oxidative stress and protein aggregation, setting in motion cascades that cause slowly developing MN degeneration.

It is interesting that these mice, however, do not develop classical clinical ALS, in which disease (associated with severe MN degeneration) progresses rapidly and contiguously from one or multiple sites. Perhaps clinical ALS occurs when dysfunction of MNs and surrounding astrocytes in a region of tissue exceeds a threshold necessary to maintain cellular energy balance and ionic homeostasis, resulting in feed forward cascades and propagation of the injury front across the compromised tissue.

Of note, human ALS is typically a disease of aging adults and the VCP mutation may accelerate events (including TDP43 aggregation and MN loss) that occur far more slowly with normal aging. Might these VCP mice, in which extensive ALSlike patholological changes develop slowly over their lifespans without frank disease, thus provide valuable models for the study of ways in which ALS risk genes of partial penetrance may accelerate age-associated changes and bring spinal cord tissue to a level of dysfunction that may on occasion trigger onset of characteristic rapidly progressive disease? Comparative studies in these and other available ALS animal models may enable breakthroughs in the understanding of common and essential mechanisms of disease and the testing of therapeutic or preventative interventions.

\begin{abstract}
Materials and Methods
Vertebrate animals. This study was carried out in strict accordance with the recommendations in the Guide for the Care and Use of Laboratory Animals of the National Institutes of Health. The protocol was approved by the Institutional Animal Care and Use Committee of the University of California, Irvine (Protocol number: 1997-1267). All procedures were terminal and all animals were deeply anethetized before starting any procedures to minimize suffering.
\end{abstract}

VCP $\boldsymbol{P}^{R 155 H /+}$ knock-in mice. In order to generate a VCP disease mouse model, a genomic VCP fragment with $7.9 \mathrm{~kb}$ of upstream homology sequence and $2.1 \mathrm{~kb}$ of downstream homology sequence was sub-cloned into a targeting vector. Site-directed mutagenesis using Quick-Change XL Site-Directed Mutagenesis Kit (Stratagene, La Jolla, CA, USA) was used to introduce the $\mathrm{R}$ to $\mathrm{H}$ mutation at amino acid position 155. The knock-in mouse model with the R155H VCP mutation was generated at InGenious Targeting Laboratory, Inc. (Stony Brook, NY, USA) through a Neomycin cassette insertion using 129/SvEv mice. The expression of mutant VCP was confirmed by RT-PCR using the following primers in the PCR reactions: forward 5'-CACGGTGTTGCTAAAAGGAAAGAAAAG-3'; reverse $3^{\prime}$-CTGAAGAATCTCCAAACGTCCTGTAGC- $5^{\prime}$, after the RT reactions with the reverse primer. These mice were backcrossed $>6$ times with the $\mathrm{C} 57 \mathrm{BL} / 6$ strain before experiments were done to make sure that the majority $(>98 \%)$ of the genetic background of generated mice was of C57BL/6 origin. The Neomycin cassette was deleted by crossing with the Flp deletion mouse model. Genotyping is carried out as described. ${ }^{12}$ Heterozygotes are bred with heterozygotes, such that half the progeny are heterozygotes, and a quarter each WT and homozygotes. For all studies, age and gender matched WT siblings are used as controls.

Strength testing. Muscle strength of the forelimbs of mice was measured using a Grip Strength Meter apparatus (TSE Systems Gmbh, Hamburg, Germany). As described (Figure 1), 14-16 WT animals and $12 \mathrm{VCP} 155 \mathrm{H} /+$ animals were examined at each age and the strongest force of 5 trails for each animal at each age was used for analysis. Statistical analyses were performed by Student's $t$-test. 
Tissue immunohistochemistry. Animals were perfused transcardially with phosphate-buffered saline (PBS), followed by $4 \%$ paraformaldehyde (PFA) for $10 \mathrm{~min}$. The brain and spinal cord were dissected and post fixed in 4\% PFA for $48 \mathrm{~h}$ and removed to $30 \%$ sucrose/PBS for another $2-3$ days. Serial $20 \mu \mathrm{m}$ frozen sections were cut from the lumbar enlargement of spinal cord. For immunostaining, sections were blocked (10\% HS and 0.3\% Triton-X 100, $1 \mathrm{~h}$ ) and exposed to monoclonal SMI-32 (1:5000; Sternberger Monoclonals, Berkeley, CA, USA) or anti-cytochrome oxidase subunit IV (COX-IV; 1:100; ab14744; Abcam, Cambridge, MA, USA), or to polyclonal antibodies against TARDBP/ TDP-43 (1:1000 for immunoperoxidase, 1:200 for immunofluorescence; ab41972; Abcam), glial fibrillary acidic protein (GFAP; 1:500; G9269; Sigma-Aldrich, St Louis, MO, USA), SQSTMI/p62 (1:3000; ab91526; Abcam) or 3-NT (1:250; 06-284; Upstate Biotechnology, Waltham, MA, USA) in blocking solution $\left(48-72 \mathrm{~h}, 4^{\circ} \mathrm{C}\right)$. Slices were then incubated with an appropriate biotinylated (Vector Laboratoroes, Burlingame, CA, USA), or fluorescent secondary antibody (DyLight 488 or 594 fluorophores; Jackson ImmunoResearch, West Grove, PA, USA). Immunoperoxidase labeling was visualized using $\mathrm{ABC}$ solution (Vector Labratories) and diaminobenzidine, and immunofluorescence labeling was visualized under fluorescence microscopy. Specificity of all immunostains was confirmed by deletion of primary antibody.

For toluidine blue staining, the slide was flooded with $0.02 \%$ Toluidine Blue 0 (Fisher Chemical, Hudson, NH, USA) for $1.5 \mathrm{~min}$, washed, and flooded with $95 \%$ ethanol to remove excess dye. For muscle studies, quadriceps muscle was embedded in cryo-sectioning media and 5-10 $\mu \mathrm{m}$ cryostat sections produced and stained with hematoxylin and eosin.

Western blotting. Spinal cords were harvested and extracted using the NEPER Nuclear and Cytoplasmic Extraction Kit (Thermo Scientific, Rockford, IL, USA). Protein concentrations were determined using the Nanodrop according to the manufacturer's protocols. Equal amount of proteins were separated on Bis-Tris $4-12 \%$ NuPAGE gels, and the expression levels of proteins were analyzed by western blotting using specific antibodies against VCP (Affinity BioReagents, Golden, CO, USA) or TDP-43 (Abcam). Alpha tubulin (Sigma-Aldrich) was used for loading control.

Quantification of histopathological changes. Quantification of measures (including MN survival, astrogliosis, cytosolic TDP-43 aggregation, and 3-NT labeling) was based upon compilations of data from a total of 28 animals (17 male, 11 female). In each study (comprising comparisons of age matched groups of WT and VCP ${ }^{\mathrm{R} 155 \mathrm{H} /}+$ mice), the gender compositions of the WT and mutant groups were identical.

Surviving MNs or reactive astrocytes were counted in ventral horn of lumbar spinal slices from each condition. MN numbers are presented as mean surviving MNs per section (comprising 2 ventral horns), and GFAP labeled reactive astrocytes calculated as numbers per unit area of ventral horn, normalized to the number present in WTs of the youngest age. MNs with pyknotic nuclei, or with a markedly atrophic, irregular or fragmented soma were not counted as alive.

Quantitative assessment of TDP-43 pathology was carried out by rating each ventral horn MN in examined sections according to a 5-point scale as follows: 0 , no cytosolic TDP-43; 1, faint diffuse cytosolic label; 2, some granularity of cytosolic labeling with no clear aggregate; 3 , some clear cytosolic TDP-43 aggregation; and 4, large and dense cytosolic TDP-43 aggregates.

For quantification of 3-NT labeling intensity, sections from matched WT and transgenic animals were identically labeled and photographed, and two regions were marked around each MN: one immediately outlining the circumfrence of the $\mathrm{MN}$ and another $10 \mu \mathrm{m}$ further out. The space between these regions was defined as the surround zone. After subtraction of background fluorescence, averaged intensity was calculated within each MN soma, and in the surround zone (8 bit intensity scale, Image J software, Public Domain software from the $\mathrm{NIH}$ ).

EMG studies. Terminal EMG study was performed on these animals at an average age of $26.68 \pm 0.47$ months for the WT (N-4) and $24.98 \pm 0.41$ months for the VCP ${ }^{R 155 H /+}$ mice $(N=4)$. Subdermal EEG electrodes were used for conducting EMG studies. The active and reference electrodes were paired together to act as a concentric needle electrode for these recordings. In each animal, the following seven muscles were sampled: unilateral thoracic paraspinal, bilateral tibialis anterior, bilateral medial gastrocnemius, and bilateral hamstrings. All recordings were made using a Cadwell Sierra LT machine (Cadwell Laboratories, Kennewich, WA, USA). Patterns of insertional and spontaneous activity were noted along with patterns of motor unit potentials evoked by movement of limbs caused by noxious footpad stimuli.

\section{Conflict of Interest}

The authors declare no conflict of interest.

Acknowledgements. This work was supported by National Institutes of Health grants NS36548 (JHW) and AR050236 (VEK), and a grant from the Muscular Dystrophy Association (VEK). We appreciate the work of Drs. Watts, Vesa and Badadani who performed the preliminary characterization studies of the $\mathrm{R} 155 \mathrm{H}$ knock-in mice.

1. Rothstein JD. Current hypotheses for the underlying biology of amyotrophic lateral sclerosis. Ann Neurol 2009; 65(Suppl 1): S3-S9.

2. Manfredi $G, X u Z$. Mitochondrial dysfunction and its role in motor neuron degeneration in ALS. Mitochondrion 2005; 5: 77-87.

3. Neumann M, Sampathu DM, Kwong LK, Truax AC, Micsenyi MC, Chou TT et al. Ubiquitinated TDP-43 in frontotemporal lobar degeneration and amyotrophic lateral sclerosis. Science 2006; 314: 130-133.

4. Sreedharan J, Blair IP, Tripathi VB, Hu X, Vance C, Rogelj B et al. TDP-43 mutations in familial and sporadic amyotrophic lateral sclerosis. Science 2008; 319: 1668-1672.

5. Chen-Plotkin AS, Lee VM, Trojanowski JQ. TAR DNA-binding protein 43 in neurodegenerative disease. Nat Rev Neurol 2010; 6: 211-220.

6. Lagier-Tourenne C, Polymenidou M, Cleveland DW. TDP-43 and FUS/TLS: emerging roles in RNA processing and neurodegeneration. Hum Mol Genet 2010; 19: R46-R64.

7. Wegorzewska I, Baloh RH. TDP-43-Based Animal Models of Neurodegeneration: New Insights into ALS Pathology and Pathophysiology. Neurodegener Dis 2011; 8: 262-274.

8. Baloh RH. TDP-43: the relationship between protein aggregation and neurodegeneration in amyotrophic lateral sclerosis and frontotemporal lobar degeneration. Febs J 2011; 278: 3539-3549

9. Watts GD, Wymer J, Kovach MJ, Mehta SG, Mumm S, Darvish D et al. Inclusion body myopathy associated with Paget disease of bone and frontotemporal dementia is caused by mutant valosin-containing protein. Nat Genet 2004; 36: 377-381

10. Kimonis VE, Mehta SG, Fulchiero EC, Thomasova D, Pasquali M, Boycott $\mathrm{K}$ et al. Clinical studies in familial VCP myopathy associated with Paget disease of bone and frontotemporal dementia. Am J Med Genet A 2008; 146A: 745-757.

11. Johnson JO, Mandrioli J, Benatar M, Abramzon Y, Van Deerlin VM, Trojanowski JQ et al. Exome sequencing reveals VCP mutations as a cause of familial ALS. Neuron 2010; 68: 857-864.

12. Badadani M, Nalbandian A, Watts GD, Vesa J, Kitazawa M, Su H et al. VCP associated inclusion body myopathy and paget disease of bone knock-in mouse model exhibits tissue pathology typical of human disease. PLoS One 2010; 5: pii: e13183.

13. Custer SK, Neumann M, Lu H, Wright AC, Taylor JP. Transgenic mice expressing mutant forms VCP/p97 recapitulate the full spectrum of IBMPFD including degeneration in muscle, brain and bone. Hum Mol Genet 2010; 19: 1741-1755.

14. Nalbandian A, Llewellyn KJ, Badadani M, Yin HZ, Nguyen C, Mukherjee $\mathrm{J}$ et al. A progressive translational mouse model of human VCP disease: The VCPR155H/ + Mouse. Muscle Nerve 2012; doi:10.1002/mus.23522.

15. Carriedo SG, Yin HZ, Weiss JH. Motor neurons are selectively vulnerable to AMPA/kainate receptor-mediated injury in vitro. J Neurosci 1996; 16: 4069-4079.

16. Geser F, Robinson JL, Malunda JA, Xie SX, Clark CM, Kwong LK et al. Pathological 43$\mathrm{kDa}$ transactivation response DNA-binding protein in older adults with and without severe mental illness. Arch Neurol 2010; 67: 1238-1250.

17. Fecto F, Siddique T. Making Connections: Pathology and Genetics Link Amyotrophic Lateral Sclerosis with Frontotemporal Lobe Dementia. J Mol Neurosci 2011; 45: 663-675.

18. Tu PH, Raju P, Robinson KA, Gurney ME, Trojanowski JQ, Lee VM. Transgenic mice carrying a human mutant superoxide dismutase transgene develop neuronal cytoskeletal pathology resembling human amyotrophic lateral sclerosis lesions. Proc Natl Acad Sci USA 1996; 93: 3155-3160.

19. Rao SD, Yin HZ, Weiss JH. Disruption of glial glutamate transport by reactive oxygen species produced in motor neurons. J Neurosci 2003; 23: 2627-2633.

20. Yin HZ, Tang DT, Weiss JH. Intrathecal infusion of a Ca2 + permeable AMPA channel blocker slows loss of both motor neurons and of the astrocyte glutamate transporter, GLT-1 in a mutant SOD1 rat model of ALS. Exp Neurol 2007; 207: 177-185.

21. Halawani D, Latterich M. p97: the cell's molecular purgatory? Mol Cell 2006; 22: 713-717.

22. Ju JS, Fuentealba RA, Miller SE, Jackson E, Piwnica-Worms D, Baloh RH et al. Valosincontaining protein (VCP) is required for autophagy and is disrupted in VCP disease. J Cell Biol 2009; 187: 875-888.

23. Deng HX, Chen W, Hong ST, Boycott KM, Gorrie GH, Siddique N et al. Mutations in UBQLN2 cause dominant X-linked juvenile and adult-onset ALS and ALS/dementia. Nature 2011; 477: 211-215.

24. Maruyama $\mathrm{H}$, Morino $\mathrm{H}$, Ito $\mathrm{H}$, Izumi $\mathrm{Y}$, Kato $\mathrm{H}$, Watanabe $\mathrm{Y}$ et al. Mutations of optineurin in amyotrophic lateral sclerosis. Nature 2010; 465: 223-226.

25. Fecto $F$, Yan J, Vemula SP, Liu E, Yang Y, Chen W et al. SQSTM1 Mutations in Familial and Sporadic Amyotrophic Lateral Sclerosis. Arch Neurol 2011; 68: 1440-1446. 
26. Philips $T$, Robberecht $W$. Neuroinflammation in amyotrophic lateral sclerosis: role of glial activation in motor neuron disease. Lancet Neurol 2011; 10: 253-263.

27. Shan X, Chiang PM, Price DL, Wong PC. Altered distributions of Gemini of coiled bodies and mitochondria in motor neurons of TDP-43 transgenic mice. Proc Natl Acad Sci USA 2010; 107: 16325-16330.

28. Xu YF, Gendron TF, Zhang YJ, Lin WL, D'Alton S, Sheng H et al. Wild-type human TDP-43 expression causes TDP-43 phosphorylation, mitochondrial aggregation, motor deficits, and early mortality in transgenic mice. J Neurosci 2010; 30: 10851-10859.

29. Van Den Bosch L, Vandenberghe W, Klaassen H, Van Houtte E, Robberecht W. Ca(2+)permeable AMPA receptors and selective vulnerability of motor neurons. J Neurol Sci 2000; 180: 29-34.

30. Alexianu ME, Ho BK, Mohamed AH, La Bella V, Smith RG, Appel SH. The role of calciumbinding proteins in selective motoneuron vulnerability in amyotrophic lateral sclerosis. Ann Neurol 1994; 36: 846-858.

31. Vanselow BK, Keller BU. Calcium dynamics and buffering in oculomotor neurones from mouse that are particularly resistant during amyotrophic lateral sclerosis (ALS)-related motoneurone disease. J Physiol 2000; 525(Pt 2): 433-445.

32. Carriedo SG, Sensi SL, Yin HZ, Weiss JH. AMPA exposures induce mitochondrial $\mathrm{Ca}(2+)$ overload and ROS generation in spinal motor neurons in vitro. J Neurosci 2000; 20 240-250.

33. Furukawa Y, Fu R, Deng HX, Siddique T, O'Halloran TV. Disulfide cross-linked protein represents a significant fraction of ALS-associated $\mathrm{Cu}, \mathrm{Zn}$-superoxide dismutase aggregates in spinal cords of model mice. Proc Natl Acad Sci USA 2006; 103: 7148-7153.

34. Niwa J, Yamada S, Ishigaki S, Sone J, Takahashi M, Katsuno M et al. Disulfide bond mediates aggregation, toxicity, and ubiquitylation of familial amyotrophic lateral sclerosislinked mutant SOD1. J Biol Chem 2007; 282: 28087-28095.
35. Colombrita C, Zennaro E, Fallini C, Weber M, Sommacal A, Buratti E et al. TDP-43 is recruited to stress granules in conditions of oxidative insult. J Neurochem 2009; 111: 1051-1061.

36. Ayala V, Granado-Serrano AB, Cacabelos D, Naudi A, llieva EV, Boada J et al. Cell stress induces TDP-43 pathological changes associated with ERK1/2 dysfunction: implications in ALS. Acta Neuropathol 2011; 122: 259-270.

37. Deng HX, Shi Y, Furukawa Y, Zhai H, Fu R, Liu E et al. Conversion to the amyotrophic lateral sclerosis phenotype is associated with intermolecular linked insoluble aggregates of SOD1 in mitochondria. Proc Natl Acad Sci USA 2006; 103: 7142-7147.

38. Ferri A, Fiorenzo P, Nencini M, Cozzolino M, Pesaresi MG, Valle $C$ et al. Glutaredoxin 2 prevents aggregation of mutant SOD1 in mitochondria and abolishes its toxicity. Hum Mol Genet 2010; 19: 4529-4542.

39. Duan W, Li X, Shi J, Guo Y, Li Z, Li C. Mutant TAR DNA-binding protein-43 induces oxidative injury in motor neuron-like cell. Neuroscience 2010; 169: 1621-1629.

40. Braun RJ, Sommer C, Carmona-Gutierrez D, Khoury CM, Ring J, Buttner S et al. Neurotoxic 43-kDa TAR DNA-binding protein (TDP-43) triggers mitochondrion-dependent programmed cell death in yeast. J Biol Chem 2011; 286: 19958-19972.

41. Rao SD, Weiss JH. Excitotoxic and oxidative cross-talk between motor neurons and glia in ALS pathogenesis. Trends Neurosci 2004; 27: 17-23.

Cell Death and Disease is an open-access journal published by Nature Publishing Group. This work is licensed under the Creative Commons Attribution-NonCommercial-No Derivative Works 3.0 Unported License. To view a copy of this license, visit http://creativecommons.org/licenses/by-nc-nd/3.0/ 